\title{
Select Histologic Type
}

National Cancer Institute

\section{Source}

National Cancer Institute. Select Histologic Type. NCI Thesaurus. Code C159684.

A direction to select one of the listed histologic sites. 